\title{
Free volatile compounds in red and purple roselle (Hibiscus sabdariffa) pomace from Indonesia
}

\author{
${ }^{1 * N i n g r u m, ~ A ., ~}{ }^{2}$ Schreiner, M., ${ }^{3}$ Luna, P., ${ }^{4}$ Khoerunnisa, F. and ${ }^{5}$ Tienkink, E. \\ ${ }^{1}$ Department of Food Science and Agricultural Product Technology, Faculty of Agricultural Technology, \\ Gadjah Mada University, Yogyakarta 55281 \\ ${ }^{2}$ Institute of Food Science, University of Natural Resources and Applied Life Science, Vienna, Austria \\ ${ }^{3}$ Indonesian Center for Agricultural Postharvest Research and Development (ICAPRD) \\ ${ }^{4}$ Department of Chemistry, Faculty of Mathematics and Science, Indonesia University of Education, \\ Bandung, 40522, Indonesia \\ ${ }^{5}$ Research Center for Crystalline Material, Sunway University, Malaysia
}

\begin{abstract}
Article history:
Received: 26 March 2019

Received in revised form: 8

May 2019

Accepted: 11 May 2019

Available Online: 1 June

2019
\end{abstract}

Keywords:

Valorization,

Tropical Fruits,

Aroma,

Headspace Solid Phase

Microextraction,

Gas Chromatography-Mass

Spectrophotometry

DOI:

https://doi.org/10.26656/fr.2017.3(6).133

\begin{abstract}
Manual headspace solid-phase microextraction (HS-SPME) coupled to gas chromatography-mass spectrophotometry (GC-MS) was used for the qualitative analysis of the aromas of several tropical fruits from Indonesia i.e. two different cultivars of roselle pomace (Hibiscus sabdariffa purple and red cultivar. Pomace was used as samples as a part of valorization application of agroindustry by-product. The analytes identified included aroma compounds that can be derived from several aroma precursors. A total of 16 major volatile compounds were identified from purple roselle pomace, whereas 11 major volatile compounds were identified from red roselle pomace using HS-SPME. The major free volatile compounds were dominantly derived from fatty acid compounds. PCA analysis showed the difference in the aroma profile of two different cultivars of pomace based on the cultivar. PC1 can differentiate $86.4 \%$ between two roselle pomace cultivar whereas PC2 can differentiate $9.4 \%$ between two roselle pomace cultivar. This study also provides the map for free volatile compounds of pomace in two different roselle cultivars.
\end{abstract}

\section{Introduction}

Hibiscus sabdariffa or called roselle is a tropical wild plant belonging into Malvaceae family. It is an annual or perennial plant. It has a long history of edible and medicinal uses spanning from Egypt, Sudan, Trinidad and Tobago, Mexico, China, Thailand, Malaysia, Indonesia, and India to South America (Patel, 2014). The beverages from roselle are consumed in traditional like in Africa continent a non-alcoholic beverage soborodo is prepared from the water extract of dried calyces. It is used as a folk medicine for constipation, heart ailment, high blood pressure, urinary tract infections, cancer, diabetes, and nerve disorders. In recent times. Several investigations have been conducted to establish its scientific purposes. So far, antioxidant, hypocholesterol effect, anti-obesity, hypotensive, antidiabetic, immunomodulatory, anticancer, hepatoprotective, antimicrobial, renoprotective, have got several adequate experimental evidence (Patel, 2014).

The dried calyces of Roselle are consumed worldwide in hot infusing and in cold drinks (Teruel et al., 2015). In Indonesia, commonly roselle is added with hot water and drink afterward. Several developments by developing rolled instant drink or ready to drink have been developed recently to fulfil consumer demand since roselle are rich in antioxidant compounds and other bioactive compounds for health purpose (Patel, 2014). The interest in natural antioxidants found in several plants has increased due to the worldwide increase in using plants extracts as additives in food and cosmetics, specifically to ensure the high quality and stability of lipids and lipid-containing products. These properties have very important influence on human health and also economic terms (Loranty et al., 2010).

The red anthocyanin pigments in the calyces are used as food coloring agents. The swollen calyces are the part of the plant of commercial interest as they are rich sources of Vitamin C, phytochemicals and are also used for several purposes. Several products like jellies and jams made from roselle which are said to taste like an acidic plume jam. Several bioactive compounds are found in Roselle e,g. anthocyanins, carotenoids, riboflavin, thiamine, niacin, ascorbic, malic and hibiscus 
acids (Jung and Joo, 2013). The fleshy calyces (sepals) are commercially important for the production of several food products from beverages, juices, jams and syrup in food industries (Borrás-linares et al., 2015).

Volatile part of foods is essential for the quality of food product. The flavor of a certain product which is one of the important attributes for sensory analysis and consumer's acceptance is given by the combination of (usually) many volatile molecules. In several fruits and vegetables, the volatiles representing their characteristic flavoris generally can come from esters, aldehydes, alcohols, terpenes, norisoprenoids and other derivatives (Bicas et al., 2011). Sometimes, one substance alone can reflect the approximate flavor of a product and in this case, the compound can be called as aroma impact compound. Several aroma impact compounds are extremely important for industry and commonly used for the elaboration of different products, from foods, beverages and cosmetics to perfumes. Recently, several studies on the production of flavor compounds from agro -industry by-product have been well supported because it is an alternative way to dispose of and valorize the waste. This is also been extensively investigated for the production of flavours by biotransformation using agroresidues as the substrates in most biological processes. This rising trend to overcome high manufacturing costs in the production of flavors is by using agrowaste as the substrate (Zamzuri and Abd-Aziz, 2013; Sine, 2015).

Several pomace is an interesting resource of healthy molecules or called as bioactive compounds such as phenolic compounds, pectin and also dietary fiber (Belén et al., 2013; Madrera and Pando, 2015; Tournour et al., 2015; Zhu et al., 2015). Several pomaces also have been investigated as a source of aroma compounds. Roselle extract when consumed in moderation induced no toxic effects and is safe, thus, can be introduced in food processing and clinical practices (Patel, 2014). Drinks from roselle are commonly prepared by adding water to Roselle, but the roselle pomace afterward is commonly discarded. This pomace still contains a high amount of several bioactive compounds that can be further utilized as an example as a flavorant and fragrance application. Aroma compounds constitute one of the important parts of food additives (Madrera and Pando, 2015). This compound is one of the most influential properties when it comes to consumer preference and is mainly determined by the volatile compounds. Certain volatiles compounds can act as impact aroma compounds that are the characteristics for particular beverages, including beverages from roselle (Weldegergis et al., 2011). The appreciably variable aroma of hot and cold extract will give influence on earthy, floral, fruity relevant in roselle extract. The appealing color and acidic sweet taste or roselle extract provide, a plausible substitute for grapes deficiency affecting the wine industry in the tropics passively (Farag et al., 2015).

This research is aimed on focusing on the use of pomace from red and purple roselle from Indonesia, especially to screen the aromatic compounds in the pomace which can be used as valuable flavor compounds using HS SPME coupled to GC MS. SPME is one of true green revolution in volatiles sample preparation technique gaining a broad spectrum of applications particularly in aroma profiling in several decades. Typical headspace SPME coupled to GC procedure implicates volatile extraction and concentration on the polymeric coating of a silica fiber and will directly desorb of the loaded fiber into the GC injection port. This technique has been used in several applications to investigate aroma compounds in several tropical fruits, spices and herbs (Riu-Aumatell et al., 2004; MonteroPrado et al., 2013; Ningrum and Schreiner, 2014; Reade et al., 2014; Ningrum et al., 2015).

\section{Materials and methods}

\subsection{Materials}

Several selected pomace were used in these experiments e.g. two different cultivars of roselle (Hibiscus sabdariffa), purple and red roselle. The pomace of purple and red roselle is obtained based on the modified method of Jasna et al. (2016).

\subsection{Free volatile analysis in selected tropical fruits by HS-SPME GC MS}

One gram of pomace from red and purple roselle were grounded by a mortar and placed in $4 \mathrm{ml} \mathrm{screw-top}$ vials $(15 \times 45 \mathrm{~mm})$ with PTFE silicon septa. An equilibration time of 10 mins was selected. (Wakte et al., 2010) $\quad 65 \mu \mathrm{m} \quad$ Polydimethylsiloxane/Divinylbenzene (PDMS/DVB) fiber of $1 \mathrm{~cm}$ was selected for analysis of free volatiles (Supelco, Bellefonte, PA, USA). The fiber was conditioned as per manufacturer's guidelines, where for $65 \mu \mathrm{m}$ PDMS/DVB, conditioning temperature is $250^{\circ}$ $\mathrm{C}$ for $0.5 \mathrm{hrs}$. After conditioning, the fiber was then exposed to the headspace of the sample in a $4 \mathrm{ml}$ vial at $60^{\circ} \mathrm{C}$ for 30 mins. SPME fibers were desorbed in the injector port for $10 \mathrm{~min}$. The free volatile compounds were analyzed by GC-MS using the following temperature program: initial temperature $50^{\circ} \mathrm{C}$, maintained for $5 \mathrm{mins}$, ramped to $150^{\circ} \mathrm{C}$ at $51^{\circ} \mathrm{C} / \mathrm{min}$, ramped to $220^{\circ} \mathrm{C}$ at $40^{\circ} \mathrm{C} / \mathrm{min}$ and held for $3 \mathrm{mins}$. The mass scan range was set to $m / z \quad 40-400$ at a scan rate of $1204,6 \mathrm{scan} / \mathrm{s}$. Helium was used as carrier gas at a constant flow rate of $1.7 \mathrm{~mL} / \mathrm{min}$. GC-MS Instrument is composed to TRACE GC Ultra 2000 version 1.4 SR1 (Thermo Corporation, Austria) coupled with mass 
spectrometric detector equipped with the capillary column. The fused silica capillary columns used were coated with HP5 or BPX-70 column. The HP5 Column (Agilent USA, $30 \mathrm{~m}, 0.25 \mathrm{~mm}$ id., $0.25 \mu \mathrm{m}$ film thickness). The BPX70 (70\% CyanopropylPolysylphenylene-Siloxane) capillary column $(50 \mathrm{~m} \mathrm{x}$ $0.22 \mathrm{~mm}$ ID $\times 0.25 \mu \mathrm{m}$ film thickness) (Agilent USA). The chromatogram was evaluated by Excalibur Software Version 1.4 (Thermo) and mass spectra were composed with NIST-Library version 2005. All experiments were performed in duplicate. The identification of volatile compounds was based on comparison of the Kovats Index (KI) of a series of $n$-alkane (C7-C40) with those reported in the literature, comparison of the relative area and on comparison of the mass spectra of each component with mass spectral libraries (NIST. National Institute of Standards and Technology, Gaithersburg, MD, USA) (Xu et al., 2014)

\subsection{Data analysis using PCA}

PCA involves the transformation of a set of variables to a new coordinate system, in which the new axes are the principle components, following the direction of highest variance in the data set. These principal components are orthogonal to one another and also constructed in such a manner that the amount of residual variation decreases with the increasing number of principal components (Weldegergis et al., 2011). PCA was commonly used to objectively interpret and compare multiple independent volatile compounds that present in the roselle cultivar studied. The purpose of PCA as one of multivariate analysis in order to decrease the number of descriptors associated with the data set while still explaining the maximum amount of variability present in the data. PCA bi plots were also constructed using a statistical package Minitab 17 (Minitab Inc, USA).

\section{Results and discussion}

The aim of this research was to investigate the diversity of volatile profiles within two different roselle pomace, e.g. red and purple roselle using GC-MS and PCA as one of chemometrics assessment. Several aroma compounds were identified in Roselle that can be derived from several compounds. In Purple Roselle cultivar the aroma compounds are more varies not just from fatty acid derivatives but also from esters class. Purple roselle pomace constituted 16 major of the identified free volatiles, compared to 11 major of the identified free volatiles from red roselle pomace. Several aroma compounds in purple roselle pomace are described in Figure 1.

Generally, two different roselle pomace volatile profile was dominated by fatty acid derived volatiles with regard to the number of identified constituents, Chemically, identified volatiles belonged to fatty acids and esters. Fatty acid derived volatiles comprised the largest number of volatile constituents and amounting approximately $100 \%$ of the red roselle pomace volatiles present in both investigated samples, respectively. Volatile ester derivatives were also slightly more enriched in purple roselle pomace samples over red pomace samples (approximately $45 \%$ vs. nd, respectively) with nonadecanoic acid methyl ester as the major constituent.

Detailed information form selected aroma compounds in purple roselle pomace is described in Table 1. Chemically, several identified volatiles in purple roselle belonged to several major chemical derivatives e.g. fatty acids and esters. Several compounds as ester derivatives are identified in purple roselle, similar to previously reported by Farag et al. (2015). Another compound from ester derivatives also can be identified in purple roselle. Esters compound can influence the character of aroma in several cultivars of roselle such as white, purple and red roselle (Elrasheid et al., 2017). Thus, the highest pleasant aroma of Al-Rahad or purple roselle type could be attributed to high ester compounds content (Elrasheid et al., 2017).

In red roselle pomace cultivar, there are several aroma compounds mainly derivatives from fatty acids (Table 1). In apple pomace, the production of aroma compounds was mainly during bioconversion of polyunsaturated fatty acids by the endogenous enzyme system. The volatile classified in aldehydes and alcohols by apple peripheral tissues from in situ or added linoleic acid or linolenic acid. Amongst the apple pomace enzymes involved in aroma production, lipoxygenase catalysis of fatty acid to produce aldehydes or alcohol compounds, on the other hand, hydroperoxidelyase will ensure also to the formation of aldehydes and alcohol compounds (Almosnino et al., 1996). The volatile compounds of red roselle are described in Figure 2. There were eleven major volatile compounds identified in Figure 2.

Detailed information form selected aroma compounds in red roselle pomace is described in Table 2. The previous investigation also showed that generally Roselle volatile profile was dominated by fatty acid derived volatiles (Farag et al., 2015).

Figure $3 \mathrm{~A}$ and $3 \mathrm{~B}$ showed the score and loading plot of PCA (Principle Component Analysis) from two different cultivars of Roselle. The purple roselle pomace has slightly higher volatile metabolites rather than the red roselle. The PCA score plots loadings plot (Figure 3B) shows the first and second principal component of 


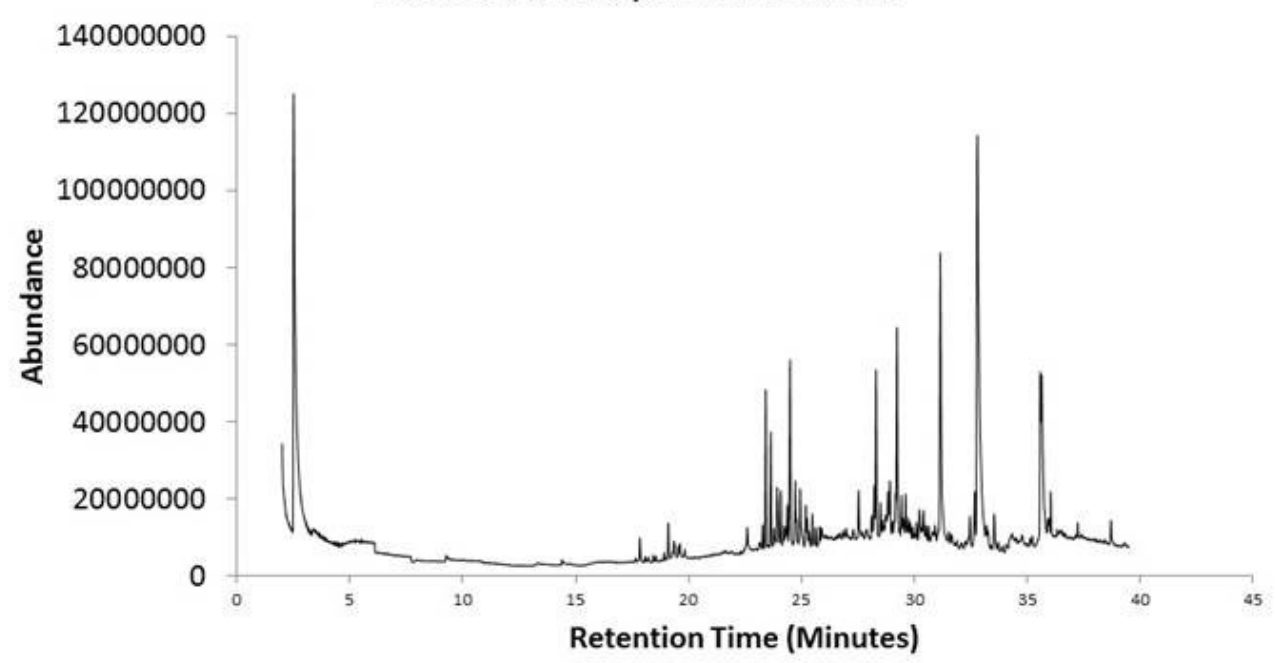

Figure 1. GC Chromatogram of Purple Roselle

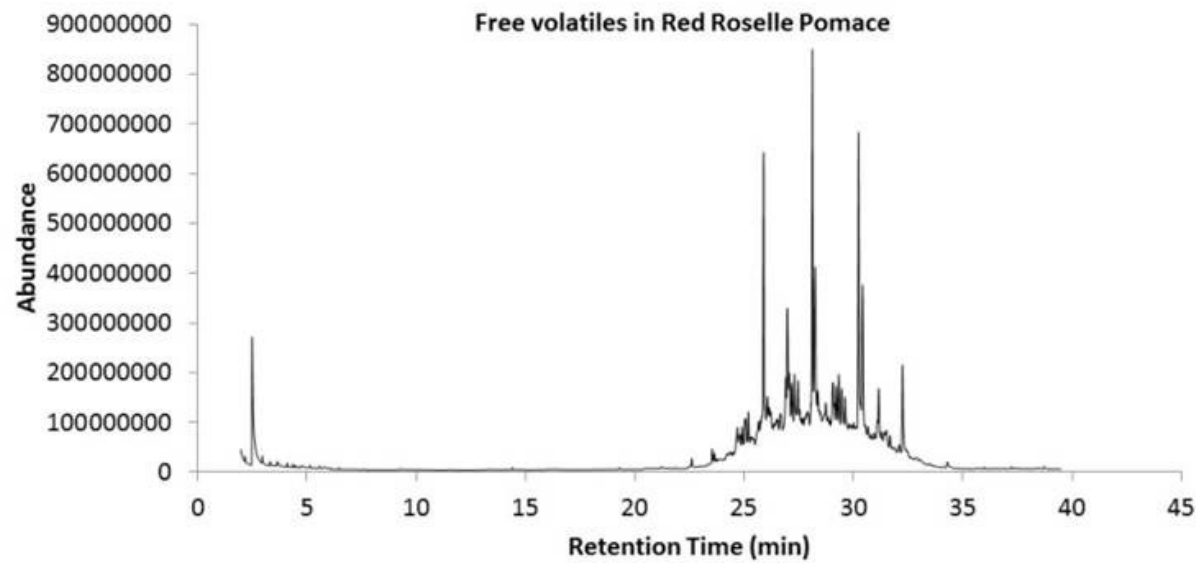

Figure 2. GC Chromatogram of Red Roselle
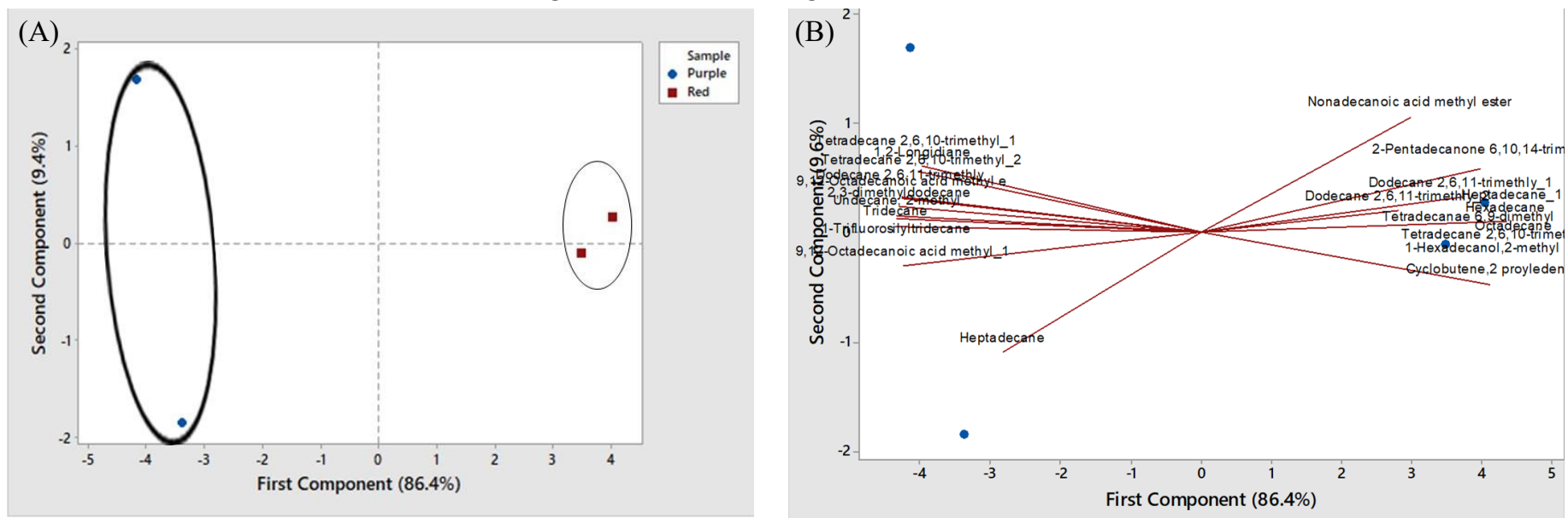

Figure 3. PCA Score Plot (3A) and Loading Plot (3B) of Purple and Red Roselle

the mean centre metabolite concentrations, which together explained more that $90 \%$ of-of the total variance. The first axis (PC1) described $86.4 \%$ of the variance and mainly discriminated esters derivatives with positives scores and negatives score from fatty acid derivatives. The second axis (PC2) described $9.4 \%$ of the variance with positive scores to mainly the compound from ester derivatives and mostly fatty acid derivatives, where negative score from minor fatty acid derivatives (heptadecane).

\section{Conclusion}

Two different roselle pomace contains diversely free volatile compounds. The free volatile compounds were extracted from two different roselle pomace using SPME and afterward analyzed using GC-MS. Total of 16 major free volatile compounds was identified from purple roselle pomace and 11 major free volatile compounds were identified from red roselle pomace. These volatile compounds can be derived from precursors such as fatty acids are important to the formation of volatile 
Table 1. Aroma components in Purple Roselle Pomace

\begin{tabular}{|c|c|c|c|c|}
\hline No & KI NIST & Compound & Compound derivatives & Relative Area \pm SD (\%) \\
\hline 1 & 735 & Cyclobutene,2-propenyldiene & FA & $58.84 \pm 0.25$ \\
\hline 2 & 1150 & Undecane, 2-methyl & FA & $1.50 \pm 0.30$ \\
\hline 3 & 1313 & Tridecane & FA & $2.02 \pm 0.55$ \\
\hline 4 & 1142 & 1-Trifluorosilyltridecane & FA & $1.71 \pm 0.37$ \\
\hline 5 & 1285 & 2,3-dimethyldodecane & FA & $6.98 \pm 1.03$ \\
\hline 6 & 1794 & 1,2-Longidiane & FA & $3.30 \pm 0.62$ \\
\hline 7 & 1563 & 9,12-Octadecanoic acid methyl ester & Ester & $2.36 \pm 0.17$ \\
\hline 8 & 1320 & Dodecane 2,6,11-trimethly & FA & $10.21 \pm 0.83$ \\
\hline 9 & 1320 & Dodecane 2,6,11-trimethly & FA & $4.39 \pm 0.27$ \\
\hline 10 & 1320 & Dodecane 2,6,11-trimethly & FA & $3.19 \pm 0.16$ \\
\hline 11 & 1711 & Heptadecane & FA & $4.96 \pm 0.8$ \\
\hline 12 & 1519 & Tetradecane 2,6,10-trimethyl & FA & $10.87 \pm 1.52$ \\
\hline 13 & 1539 & Tetradecane 2,6,10-trimethyl & FA & $1.80 \pm 0.34$ \\
\hline 14 & 1754 & 2-Pentadecanone 6,10,14-trimethyl & FA & $16.07 \pm 3.27$ \\
\hline 15 & 2177 & Nonadecanoic acid methyl ester & Ester & $31.70 \pm 7.11$ \\
\hline 16 & 2193 & 9,12-Octadecanoic acid methyl ester & Ester & $11.12 \pm 5.63$ \\
\hline
\end{tabular}

Table 2. Aroma components in Red Roselle Pomace

\begin{tabular}{|c|c|c|c|c|}
\hline No & KI NIST & Compound & Compound derivatives & Relative Area \pm SD (\%) \\
\hline 1 & 735 & Cyclobutene, 2 proyledene & FA & $8.31 \pm 0.96$ \\
\hline 2 & 1563 & 1 Dodecanol 3,7,11, trimethyl & FA & $1.67 \pm 0.61$ \\
\hline 3 & 1512 & Pentadecane & FA & $13.86 \pm 0.41$ \\
\hline 4 & 1512 & Tetradecanae 6,9-dimethyl & FA & $12.9 \pm 1.38$ \\
\hline 5 & 1612 & Hexadecane & FA & $18.8 \pm 2.01$ \\
\hline 6 & 1519 & Tetradecane 2,6,10-trimethyl & FA & $9.56 \pm 1.02$ \\
\hline 7 & 1890 & 1-Hexadecanol,2-methyl & FA & $3.07 \pm 0.33$ \\
\hline 8 & 1711 & Heptadecane & FA & $16.9 \pm 1.8$ \\
\hline 9 & 1810 & Octadecane & FA & $9.72 \pm 1.04$ \\
\hline 10 & 1754 & 2-Pentadecanone, $6,10,14$ trimethyl & FA & $4.86 \pm 0.52$ \\
\hline 11 & 1900 & Nonadecane & FA & $6.16 \pm 0.66$ \\
\hline
\end{tabular}

$* \mathrm{FA}=$ Fatty Acids

compounds in two different roselle pomace cultivar. The systematic approach employed in this work has allowed us to focus on the identification of the aroma of relevant volatile compounds in red and purple pomace of Roselle from Indonesia. These compounds are valuable as potential markers for a different cultivar of Roselle pomace

\section{Conflict of Interest}

The authors declare no conflict of interest in the manuscript.

\section{Acknowledgment}

Authors thankful to Kemenristek DIKTI Indonesia by WCP Scheme A Program, Toray Foundation and Prof. Edward R.T. Tiekink and Research Centre of Crystaline Material, Sunway University, Malaysia for supporting this research.

\section{References}

Almosnino, A.M., Bensoussad, M. and Belid, J.M. (1996). Unsaturated fatty acid bioconversion by apple pomace enzyme system. Factors influencing the production of aroma compounds, 55(4), 327332.

Belén, A., Alvarado, O., Ory, I.D., Caro, I. and Blandino, A. (2013). Food and Bioproducts Processing Valorization of grape pomace and orange peels: Improved production of hydrolytic enzymes for the clarification of orange juice. Food and Bioproducts Processing, 91(4), 580-586. https://doi.org/10.1016/ j.fbp.2013.01.007

Bicas, J.L., Molina, G., Dionísio, A.P., Barros, F.F.C., Wagner, R., Maróstica, M.R. and Pastore, G.M. (2011). Volatile constituents of exotic fruits from Brazil. Food Research International, 44(7), 18431855. https://doi.org/10.1016/j.foodres.2011.01.012

Borrás-linares, I., Fernández-arroyo, S., Arráez-roman, D. and Palmeros-suárez, P.A. (2015). Characterization of phenolic compounds, anthocyanidin, antioxidant and antimicrobial activity of 25 varieties of Mexican Roselle (Hibiscus sabdariffa ). Industrial Crops and Products, 69, 385394. https://doi.org/10.1016/j.indcrop.2015.02.053

Elrasheid, H., Zou, T., Abdalbasit, X. and Mariod, A. (2017). Assessment of antioxidant properties, instrumental and sensory aroma profile of red and white Karkade/Roselle (Hibiscus sabdariffa L .). 
Journal of Food Measurement and Characterization, 11(4), 1559-1568. https://doi.org/10.1007/s11694017-9535-0

Farag, M.A., Rasheed, D.M. and Kamal, I.M. (2015). Volatiles and primary metabolites pro fi ling in two Hibiscus sabdariffa (roselle) cultivars via headspace SPME - GC-MS and chemometrics. Food Research International, 78, 327-335. https://doi.org/10.1016/ j.foodres.2015.09.024

Jasna, C., Pajin, B., Djilas, S., Šaponjac, V.T., Gordana, C., Lonc, I. and Vulic, J. (2016). Sour cherry pomace extract encapsulated in whey and soy proteins: Incorporation in cookies anadanovic. Food Chemistry, 207, 27-33. https://doi.org/10.1016/ j.foodchem.2016.03.082

Jung, E. and Joo, N. (2013). Roselle (Hibiscus sabdariffa L.) and soybean oil effects on quality characteristics of pork patties studied by response surface methodology. Meat Science, 94(3), 391-401. https:// doi.org/10.1016/j.meatsci.2013.02.008

Loranty, A., Rembiałkowska, E., Rosa, E.A.S. and Bennett, R.N. (2010). Journal of Food Composition and Analysis Identification, quantification and availability of carotenoids and chlorophylls in fruit, herb and medicinal teas. Journal of Food Composition and Analysis, 23(5), 432-441. https:// doi.org/10.1016/j.jfca.2010.01.007

Madrera, R.R. and Pando, R. (2015). Production and characterization of aroma compounds from apple pomace by solid-state fermentation with selected yeasts. LWT - Food Science and Technology, 64(2), 1342-1353.

https://doi.org/10.1016/ j.1wt.2015.07.056

Montero-Prado, P., Bentayeb, K. and Nerín, C. (2013). Pattern recognition of peach cultivars (Prunus persica L.) from their volatile components. Food Chemistry, 138(1), 724-731. https://doi.org/10.1016/ j.foodchem.2012.10.145

Ningrum, A., Minh, N.N. and Schreiner, M. (2015). Carotenoids and Norisoprenoids as Carotenoid Degradation Products in Pandan Leaves (Pandanus amaryllifolius Roxb.). International Journal of Food Properties, 18(9), 1905-1914. https:/ doi.org/10.1080/10942912.2014.971186

Ningrum, A. and Schreiner, M. (2014). Carotenoidcleavage activities of crude enzymes from Pandanous amryllifolius. Chemistry and Biodiversity, 11(11), 1871-1881. https:// doi.org/10.1002/cbdv.201400029

Patel, S. (2014). Hibiscus sabdariffa: An ideal yet underexploited candidate for nutraceutical applications. Biomedicine and Preventive Nutrition, 4(1), 23-27. https://doi.org/10.1016/j.bionut.2013.10.004

Reade, S., Mayor, A., Aggio, R., Khalid, T., Pritchard,
D., Ewer, A. and Probert, C. (2014). Optimisation of Sample Preparation for Direct SPME-GC-MS Analysis of Murine and Human Faecal Volatile Organic Compounds for Metabolomic Studies. Journal of Analytical and Bioanalytical Techniques, 5(2). https://doi.org/10.4172/2155-9872.1000184

Riu-Aumatell, M., Castellari, M., López-Tamames, E., Galassi, S. and Buxaderas, S. (2004). Characterisation of volatile compounds of fruit juices and nectars by HS/SPME and GC/MS. Food Chemistry, 87(4), 627-637. https://doi.org/10.1016/ j.foodchem.2003.12.033

Teruel, R.M., Garrido, M.D., Espinosa, M.C. and Linares, M.B. (2015). Effect of different formatsolvent rosemary extracts (Rosmarinus officinalis) on frozen chicken nuggets quality. Food Chemistry, 172, 40-46. https://doi.org/10.1016/ j.foodchem.2014.09.018

Sine, O. (2015). Bioflavour production from tomato and pepper pomaces by Kluyveromyces marxianus and Debaryomyces hansenii, 1143-1155. https:// doi.org/10.1007/s00449-015-1356-0

Tournour, H.H., Segundo, M.A., Magalhães, L.M., Barreiros, L., Queiroz, J. and Cunha, L.M. (2015). Valorization of grape pomace: Extraction of bioactive phenolics with antioxidant properties. Industrial Crops and Products, 74, 397-406. https:// doi.org/10.1016/j.indcrop.2015.05.055

Wakte, K.V., Thengane, R.J., Jawali, N. and Nadaf, A.B. (2010). Optimization of HS-SPME conditions for quantification of 2-acetyl-1-pyrroline and study of other volatiles in Pandanus amaryllifolius Roxb. Food Chemistry, 121(2), 595-600. https:// doi.org/10.1016/j.foodchem.2009.12.056

Weldegergis, B.T., Villiers, A.D. and Crouch, A.M. (2011). Chemometric investigation of the volatile content of young South African wines. Food Chemistry, 128(4), 1100-1109. https:// doi.org/10.1016/j.foodchem.2010.09.100

Xu, Y.X., Zhang, M., Fang, Z.X., Sun, J.C. and Wang, Y.Q. (2014). How to improve bayberry (Myrica rubra Sieb. et Zucc.) juice flavour quality: Effect of juice processing and storage on volatile compounds. Food Chemistry, 151, 40-46. https:// doi.org/10.1016/j.foodchem.2013.10.118

Zamzuri, N.A. and Abd-Aziz, S. (2013). Biovanillin from agro wastes as an alternative food flavour. Journal of the Science of Food and Agriculture, 93 (3), 429-438. https://doi.org/10.1002/jsfa.5962

Zhu, F., Du, B., Zheng, L. and Li, J. (2015). Advance on the bioactivity and potential applications of dietary fibre from grape pomace. Food Chemistry, 186, 207 -212 . https://doi.org/10.1016/ j.foodchem.2014.07.057 